\title{
Adsorption Behavior of Silk Fibroin on Amphiphilic Graphene Oxide
}

\author{
Sirimuvva Tadepalli ${ }^{1}$, Henry Hamper ${ }^{1}$, Sang Hyun Park ${ }^{1}$, Sisi Cao ${ }^{1}$, Rajesh R. Naik ${ }^{2 *}$, \\ Srikanth Singamaneni ${ }^{{ }^{*}}$ \\ ${ }^{1}$ Institute of Material Science and Engineering and Department of Mechanical Engineering and \\ Material Science, Washington University in St. Louis, St Louis, MO, 63130, USA. \\ ${ }^{2} 711$ Human Performance Wing, Wright-Patterson, Air Force Base, Dayton, $\mathrm{OH}$
}

\begin{abstract}
*To whom correspondence should be addressed: singamaneni@wustl.edu (SS) and rajesh.naik@us.af.mil (RRN)
\end{abstract}

Supporting Information 


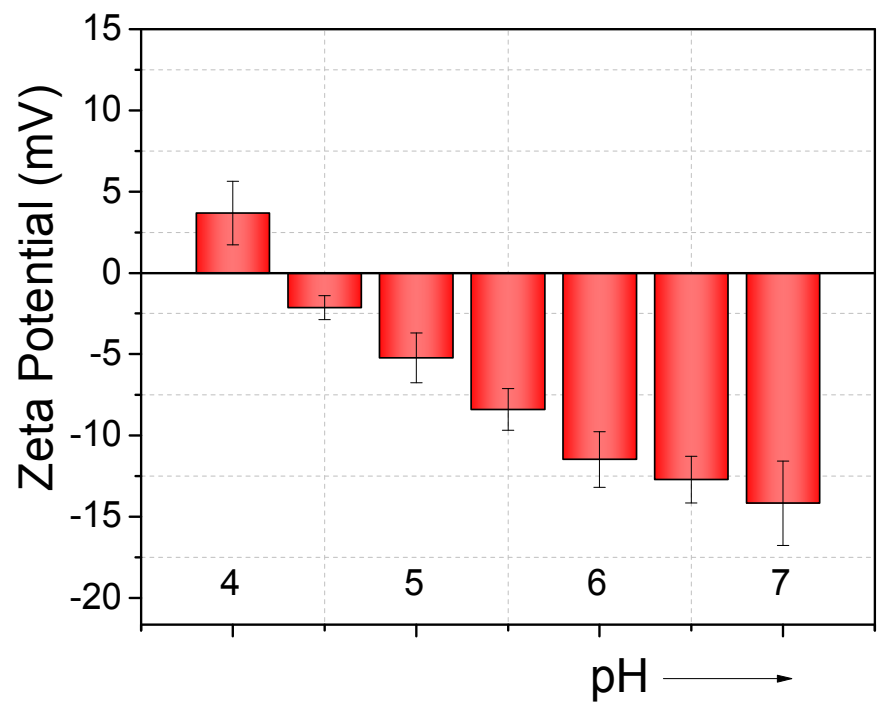

Figure S1: Zeta Potential of silk fibroin at different $\mathrm{pH}$ values. 

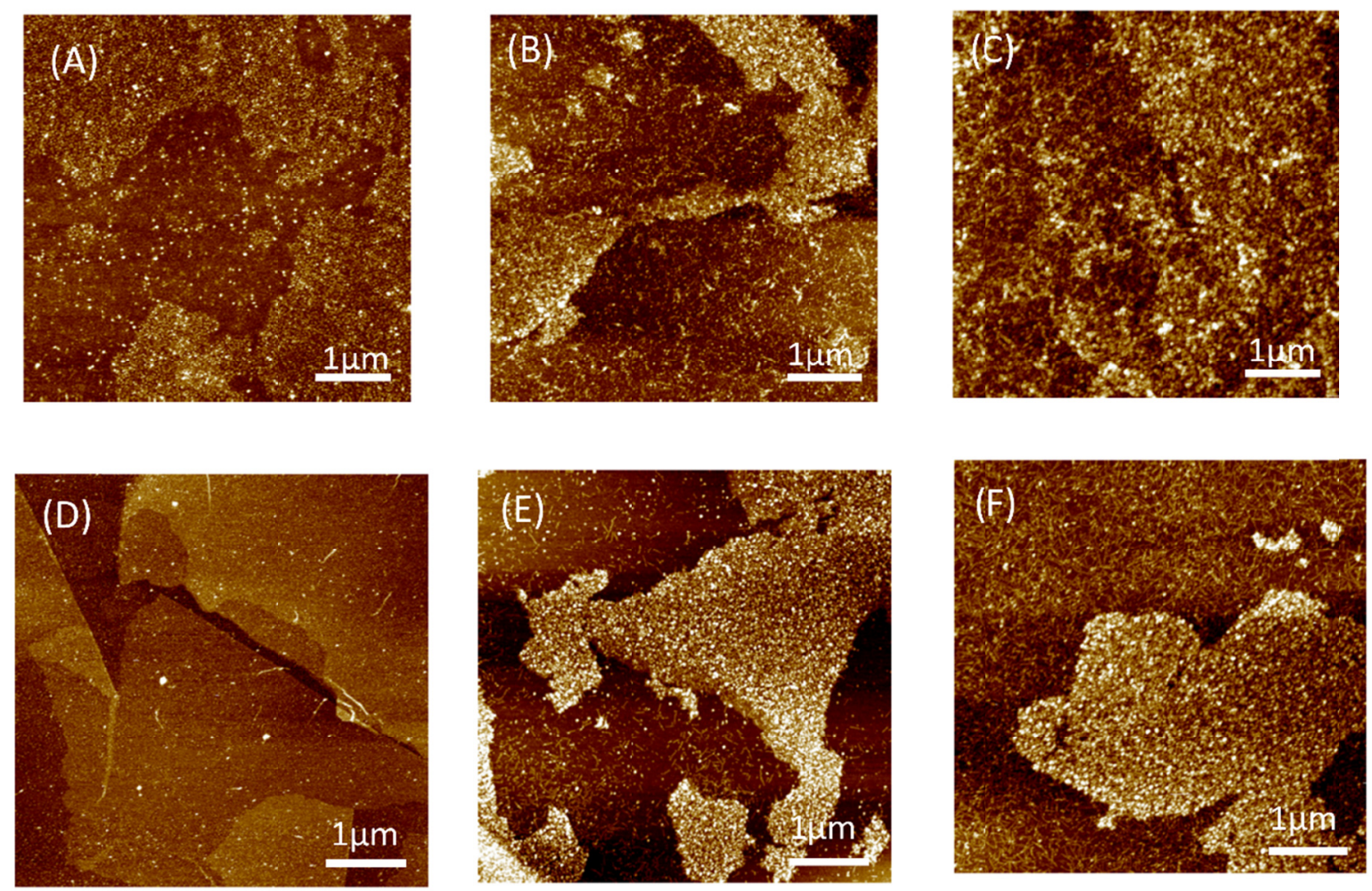

Figure S2: AFM images of silk fibroin adsorbed on GO for different incubation times (A,D) 10 seconds $(B, E) 10$ minutes $(C, F) 1$ hour at different $p H$ values $(A-C) p H 4$ and $(D-E) p H 7$. The height scale is $10 \mathrm{~nm}$ for (A), $20 \mathrm{~nm}$ for (B), 30nm for (C), $10 \mathrm{~nm}$ for (D) $12 \mathrm{~nm}$ for (E) and $15 \mathrm{~nm}$ for $(F)$. The adsorption of the silk increases with the incubation time. 

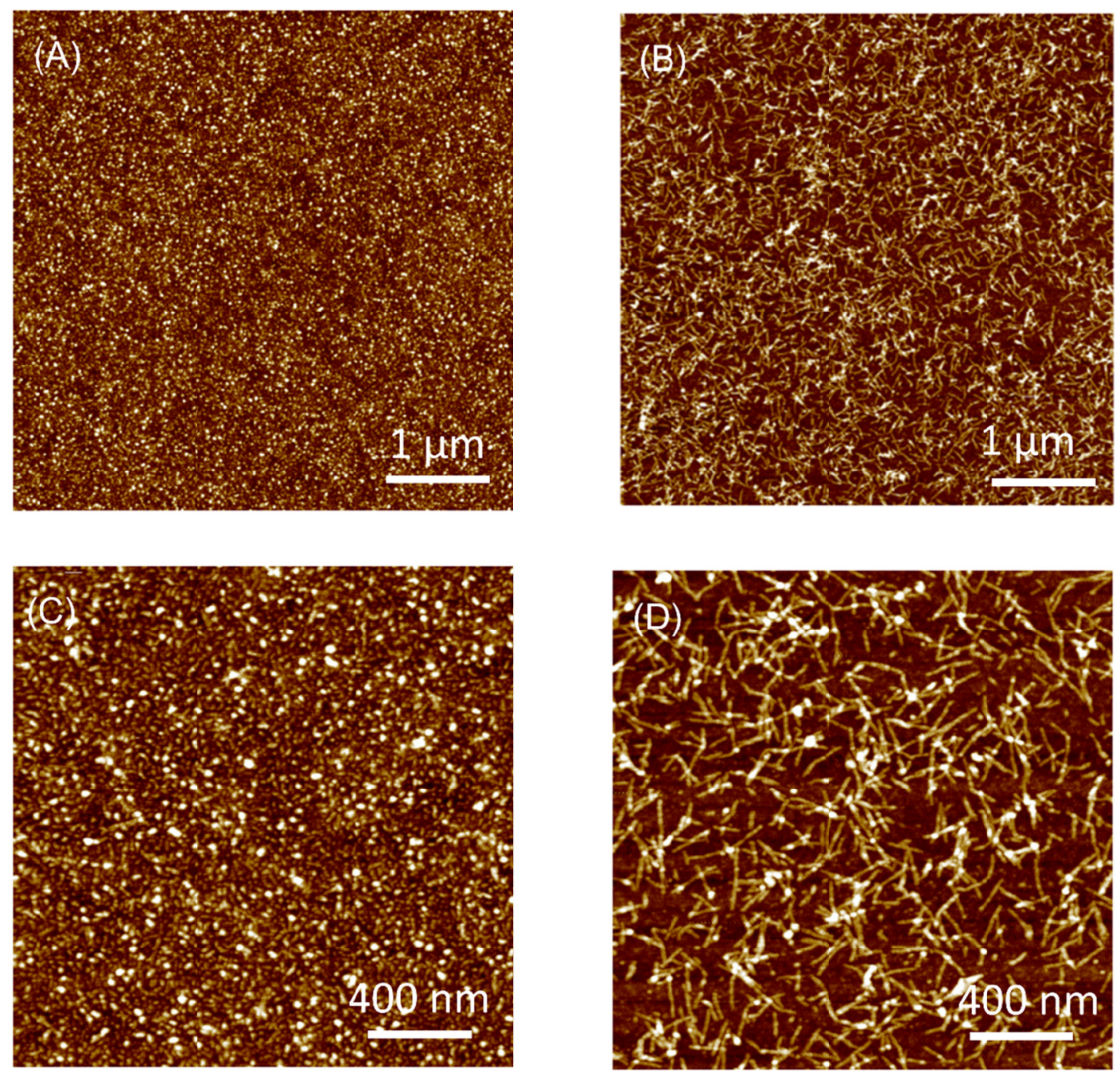

Figure S3: AFM images of silk adsorbed on a silicon substrate for extended periods of time (1 hour); $(\mathrm{A}, \mathrm{C}) \mathrm{pH} 4(\mathrm{~B}, \mathrm{D}) \mathrm{pH}$. Height scale is $10 \mathrm{~nm}$. 

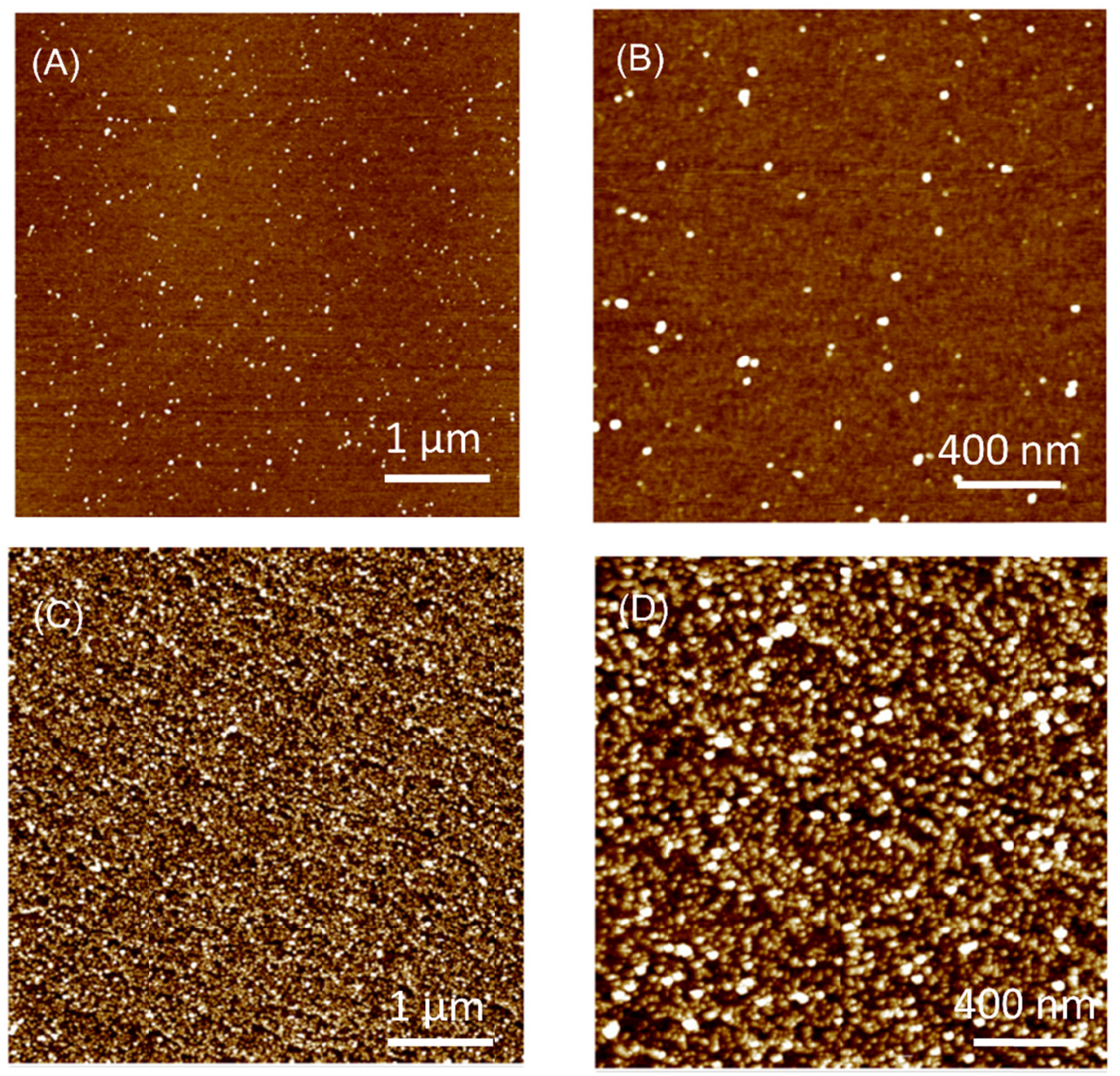

Figure S4: AFM images of silk adsorbed on positively charged (APTES-modified silicon) substrate for short incubation time (30 seconds); (A,B) $\mathrm{pH} 4(C, D) \mathrm{pH}$. Height scale is $5 \mathrm{~nm}$. 

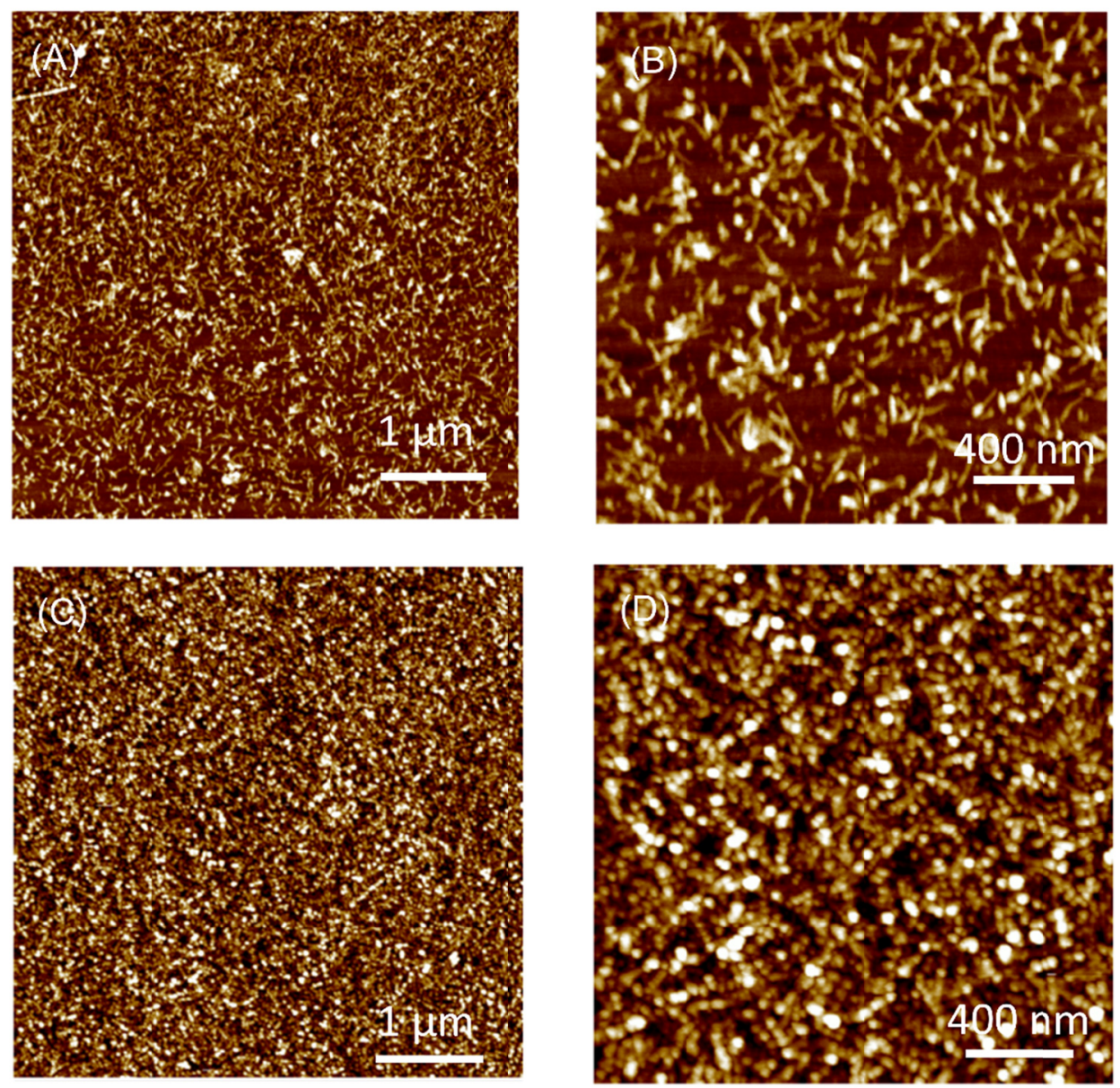

Figure S5: AFM images of silk adsorbed on positively charged (APTES-modified silicon) substrate for long incubation time (60 min); $(A, B) \mathrm{pH} 4(C, D) \mathrm{pH} 7$. Height scale is $10 \mathrm{~nm}$. 